\title{
LA MEDIACIÓN LINGÜÍSTICA INSTITUCIONALIZADA EN LAS FRONTERAS HISPANO-MAPUCHE E HISPANO-ÁRABE: ¿UN PATRÓN SIMILAR? $?^{* * *}$
}

\begin{abstract}
Las autoras proponen una indagación sobre las formas de mediación lingüística empleadas principalmente en los contextos hispano-mapuche e hispano-árabe, para poner de relieve el papel y la importancia de los cuerpos institucionalizados de intérpretes y funcionarios afines. Sometiendo la historiografía de las fronteras a la mirada de los estudios de traducción, proponen la existencia de un patrón similar en el uso de estos mediadores y sugieren los posibles canales de transmisión de este patrón.
\end{abstract}

Palabras clave: intérpretes, frontera araucana, frontera hispano-árabe.

The authors propose an exploration of the modes of linguistic mediation used in the hispanic-mapuche and hispanic-arab contexts in order to highlight the role and importance of interpreters and other institutionalized mediators. By using a translation studies approach to complement the historiography related to these frontier experiences, they propose the existence of a similar pattern for the use of linguistic mediators and suggest the existence of channels trough which this pattern was transmitted.

Key words: interpreters, araucanian frontier, hispanic-arab frontier.

Fecha de recepción: noviembre 2008

Fecha de aceptación: mayo 2009

* Universidad Católica de Temuco. Correo electrónico: payas@lagerta.com

** Universidad de Salamanca. Correo electrónico: itziar@usal.es

*** Este trabajo se enmarca en dos proyectos de investigación: por parte de ambas investigadoras, en el proyecto I+D HUM2006-05403/FILO (2006-2009): "Estudio contrastivo de las dificultades de mediación lingüística y cultural: experiencia histórica y nuevos retos en la Europa contemporánea (España, Alemania, Italia)", dirigido por el Dr. Jesús Baigorri, de la Universidad de Salamanca, y financiado por el Ministerio de Educación y Ciencia español. Asimismo, y por parte de Gertrudis Payàs, esta investigación es parte del proyecto FONDECYT N 1090954 , "Aproximación interdiciplinar a la mediación lingüística entre el mapudungun y el castellano, ss. XVII.XIX: traductología, antropología histórica y filosofía”, del que es investigadora responsable. Gertrudis Payàs agradece a José Manuel Zavala, de la Universidad Católica de Temuco, sus observaciones al texto; a Milena Grass, de la P. Universidad Católica de Chile, y a los alumnos del Seminario de investigación traductológica de la P. Universidad Católica de Valparaíso Romina Moreno y Sebastián Guajardo quienes, con sus lecturas y debates, contribuyeron a impulsar el interés por este tema desde el año 2007. Desligamos no obstante, de todo error u omisión a las personas citadas en esta nota. 
Frente a la llamada "problemática mapuche", algunas voces sostienen que hay que encontrar el camino del diálogo ${ }^{1}$. El gesto de retroceder para ver cómo se resolvieron los conflictos en tiempos coloniales no es caprichoso y merece ser profundizado. De hecho, aun con las crueldades y abusos propios de la Colonia, la existencia de la frontera araucana y las periódicas negociaciones que en ella se celebraron por vía de los parlamentos ${ }^{2}$ permiten concluir que hubo más reconocimiento de la alteridad mapuche bajo la autoridad colonial que en el periodo republicano inmediato. Uno de los elementos reveladores de esta alteridad reconocida fue el uso de mediadores lingüísticos (intérpretes y cargos afines) en las negociaciones hispano-mapuches.

A este respecto en particular, no parece ya posible una aplicabilidad de los modelos de mediación del pasado a la actualidad; sin embargo, los estudios que venimos realizando desde hace algún tiempo sobre las dificultades de comunicación interlingüística en contextos de migración modernos ${ }^{3}$ sugieren que merece la pena repasar la historia y poner en evidencia las funciones de intérpretes o agentes mediadores lingüísticos en las relaciones interétnicas, ya que pueden servirnos para comprender las dinámicas de negociación y las percepciones recíprocas de las partes en contacto ${ }^{4}$. Una primera constatación, al repasar desde esta perspectiva los estudios sobre la frontera, en particular del ámbito colonial americano ${ }^{5}$, es que hay coincidencias en las formas de relación fronteriza que nos hacen pensar en la

1 Dos ejemplos entre muchos: Alfredo Jocelyn-Holt, en la revista ¿Qué Pasa? del 11 de enero de 2008, sostenía en un artículo de divulgación, que convendría reexaminar, cómo fueron las relaciones entre españoles y mapuche en el periodo colonial para extraer de ellas enseñanzas para el presente. En la misma línea, tiempo después, en The Clinic del 21 de agosto de 2008, el periodista mapuche Pedro Cayuqueo, a propósito de los últimos encontronazos interétnicos, hacía un llamado a "parlamentar", como fue costumbre en los siglos coloniales.

2 Los parlamentos de la Araucanía han sido objeto particular de interés en Chile desde la publicación de Sergio Villalobos et al., Relaciones fronterizas en la Araucanía, Santiago, Ediciones Universidad Católica de Chile, 1982, en la que este autor propuso que las relaciones hispano-mapuches habían transitado por largos periodos de convivencia mayormente pacífica, con lo que rompió con la tradición historiográfica que había interpretado las relaciones fronterizas como permanentemente belicosas.

3 Ver, en particular, Jesús Baigorri et al., "Estudio contrastivo de las dificultades de la mediación lingüística y cultural: Experiencia histórica y nuevos retos en la Europa contemporánea (España, Alemania, Italia)", en Carmen Valero-Garcés (ed.), Investigación y práctica en traducción e interpretación en los servicios públicos. Desafíos y alianzas, Alcalá de Henares, Universidad de Alcalá, CDROM, 2008, 24-38.

4 Los estudios postcoloniales han propuesto la noción de "zona de contacto" para definir precisamente estos espacios donde el encuentro y el rechazo, la ignorancia y la influencia recíproca entre las culturas tienen lugar en un contexto de relaciones de poder asimétricas. Si bien este trabajo no se enmarca propiamente en los estudios postcoloniales, por la atención que Pratt presta al tema lingüístico y a la necesidad de una "lingüística de contacto", no queremos deslindarnos de un marco teórico que permite entender las formas en que los hablantes "se construyen mutuamente por sus relaciones y por sus diferencias, [y] cómo manifiestan estas diferencias en la lengua misma": Mary Louise Pratt, "Linguistic Utopias", en Nigel Fabb et al. (eds.), The Linguistics of Writing, Manchester, Manchester University Press, 1987, 60.

5 Véase David J. Weber, Bárbaros. Spaniards and Their Savages in the Age of Enlightenment, New Haven y Londres, Yale University Press, 2005; Fernando Operé, Historias de la frontera: El cautiverio en la América hispánica, Buenos Aires, Fondo de Cultura Económica, 2001; Pablo Lacoste, La imagen del otro en las relaciones de la Argentina y Chile (1534-2000), Buenos Aires, Fondo de Cultura Económica e Instituto de Estudios Avanzados de la Universidad de Santiago de Chile, 2003. 
posibilidad de patrones similares en lo que respecta a las formas de mediación lingüística que operaron en los siglos coloniales.

En la medida en que se trata de casos y contextos semejantes y no de anécdotas o casos excepcionales, las prácticas de interpretación en situación de frontera constituyen un campo analizable desde una sociohistoria, más que desde una historia, y, desde luego, en combinación con una mirada desde la traductología ${ }^{6}$.

La mediación oral, o interpretación, implica la intervención de uno o más hablantes políglotas para asistir en una situación de comunicación entre hablantes de lenguas distintas. Es tal la variedad de situaciones en que se ha producido, en todos los tiempos y culturas, que más que intentar clasificaciones o taxonomías resulta útil pensar en un largo continuo ${ }^{7}$ que va de los tipos de interpretación más informales a los más institucionalizados. De los primeros tendríamos, en la historia colonial americana, los casos de secuestro de indígenas para usarlos como informantes de los primeros conquistadores o exploradores, informantes que desaparecían de escena en cuanto resultaban innecesarios o inservibles. Del tipo más institucionalizado tendríamos, en el mismo contexto histórico, los casos de nombramiento oficial de nahuatlatos, en la administración de justicia novohispana, los cargos de capitán de amigos, lengua general y comisario de naciones, en las negociaciones entre españoles y población mapuche en el periodo XVII-XIX, o el caso de los cuerpos de alfaqueques o exeas, en el contexto hispano-árabe entre los siglos XIII y XVI, todos ellos sujetos a reglamentación y salario.

Trátese del caso hispano-árabe o del hispano-mapuche, pueden considerarse casos de mediación o interpretación intersocial, entre naciones, según la nomenclatura de Pöchhacker, que cabe diferenciar de la mediación o interpretación intrasocial, un ejemplo de la cual sería la que operaba en la administración de justicia colonial. Esta, si bien en el periodo colonial en particular también tuvo un carácter oficial y reglamentado, como es el caso de los intérpretes o nahuatlatos ${ }^{8}$ de las audiencias novohispanas, no se entendía como una mediación entre dos entidades que se reconocían el derecho a negociar asuntos de interés común, sino que constituía un recurso que la autoridad colonial establecía para la administración de justicia civil y penal, sobre todo como protección del indígena.

La interpretación intersocial, o entre naciones, puede ser requerida por una de las partes, que la ofrece o impone a la otra, o puede ser requerida de común acuerdo. Determinar este dato, lo que implica una indagación a fondo en las fuentes históricas, puede ayudar a comprender las funciones diversas que en un determinado evento realizan los mediadores lingüísticos.

\footnotetext{
${ }^{6}$ La traductología o estudios de traducción, disciplina que estudia la mediación lingüística oral y escrita (traducción e interpretación), como fenómeno cultural e histórico y como práctica especializada, se ha ido abriendo camino en el mundo académico desde hace algunas décadas y constituye ya un campo disciplinar consolidado. Como rama de esta disciplina, la historia de la mediación lingüística estudia, entre otros fenómenos, las dinámicas de contacto mediado, cuya complejidad y rasgos particulares han merecido en general poca atención de parte de la historiografía tradicional.

$7 \quad$ Franz Pöchhacker, Introducing interpreting studies, Londres y Nueva York, Routledge, 2004.

8 Hemos estudiado la figura del nahuatlato en Icíar Alonso y Gertrudis Payàs, "Sobre alfaqueques y nahuatlatos: Nuevas aportaciones a la historia de la interpretación”, en Valero-Garcés, op. cit.
} 
No es común en la historia colonial hispanoamericana la presencia durante largo tiempo de cuerpos de mediación lingüística institucionalizados para el trato entre naciones beligerantes, como tampoco es común la presencia de ejércitos permanentes. La rapidez con que se llevó a cabo la conquista territorial y sujeción de las poblaciones, imposición e instauración de la administración colonial, significó que muy rápidamente no quedaron "naciones enemigas" ni "naciones aliadas" con quienes negociar. Había habido necesidad de intérpretes en las campañas de conquista, pero una vez instalado el aparato burocrático, la interpretación institucional se restringe principalmente al ámbito de la administración de justicia, para las audiencias de indios y procedimientos en que intervinieran indígenas que no hablaran castellano. Fuera del ámbito civil y judicial, también se dio en todo momento actividad de interpretación al servicio de la labor evangelizadora, servicio que se daba dentro de la propia comunidad religiosa, con carácter ad hoc ${ }^{9}$.

Además de los intérpretes en la administración de justicia, los casos en que encontramos cuerpos de mediación institucionalizados en la historia colonial son característicos de las situaciones de frontera, es decir, cuando las poblaciones ofrecen resistencias a la invasión y, no pudiéndose imponer una solución militar definitiva, se establece una dinámica oscilante entre la enemistad y la alianza estratégica que puede en definitiva convenir a determinados intereses y convertirse en statu quo. En esos casos, por razones pragmáticas, los invasores optan por establecer puestos fijos, colonias militares o plazas fuertes que se reparten a lo largo de una línea de separación y sirven de resguardo a los contingentes militares, además de albergar pequeñas concentraciones de pobladores. Estas fronteras pueden convertirse en las fronteras políticas de los estados modernos, o pueden disolverse como resultado de nuevas conquistas. En el mundo hispano colonial, las fronteras fueron, principalmente: el norte de Baja California y la Chichimeca (al norte de México), el Gran Chaco (oriente boliviano, oeste de Paraguay y norte de Argentina), y la Araucanía (sur de Chile), en el extremo sur del continente ${ }^{10}$. Para el conjunto de prácticas de mediación lingüística colonial ${ }^{11}$, representan casos significativos, todavía por estudiar desde la óptica de las prácticas de negociación y tratativas mediadas por intérpretes ${ }^{12}$.

9 Casi todos los cronistas religiosos de la época hacen referencia en mayor o menor medida a las dificultades lingüísticas y modos de resolverlas. Ver, en particular, Jerónimo Mendieta, Historia Eclesiástica Indiana, edición de Joaquín García Icazbalceta, México, Antigua Librería, Portal de Agustinos, 1870 .

10 Weber, op. cit.

11 Alonso y Payàs, op. cit.

12 En los territorios de América del Norte conquistados por franceses e ingleses también fue significativa la mediación lingüística. Véase Nancy L. Hagedorn, "A friend to go between them: the interpreter as cultural broker during the Anglo-Iroquois councils, 1740-70", en Ethnohistory 31, Durham, NC, 1988, 60-80; Jean Delisle, "Jacques Cartier's interpreters", en Jerome Quarterly 9, Washington, 1993; William John Eccles, The Canadian Frontier 1534-1760, Albuquerque, University of New Mexico Press, 1985 
Por otra parte, no se ha realizado ningún estudio comparativo ni se ha explorado, que sepamos, la posible relación entre los modelos de mediación lingüística colonial y la larga práctica de mediación lingüística hispano-árabe en el contexto de la frontera castellana. El conocimiento que los españoles tenían del trato fronterizo en territorio propio venía, principalmente, del contacto prolongado con los invasores árabes. La llamada marca hispánica fue una frontera que separó efectivamente la España cristiana de los territorios bajo dominación árabe, especialmente entre los siglos XIII y XVI, y en la que se dio una dinámica de fricciones y negociaciones de componentes militares, mercantiles y religiosos similar a la que encontramos en particular en la historia chilena, con el fenómeno del cautiverio como uno de sus rasgos característicos.

En este trabajo proponemos una indagación preliminar sobre las afinidades o posibles paralelismos y modelos en los modos de mediación entre la frontera que se establece oficialmente en el Biobío después de Curalaba (XVII-XIX) y la frontera hispano-árabe, con una breve referencia a la Chichimeca mexicana.

Haciendo un somero repaso histórico, en el caso chileno, a raíz de la derrota de Curalaba, en 1598, los españoles reconsideraron la posibilidad de seguir conquistando al sur del río Biobío, que exigía un esfuerzo onerosísimo en términos económicos y de contingentes militares permanentes y, tras varias décadas de desgaste bélico, por el tratado de Quillín, en 1641, establecieron una frontera que separaba el Chile español de la nación araucana (hoy mapuche). Con los grupos mapuches, reconocidos como pueblo independiente, debieron negociar periódicamente alianzas, intercambio de cautivos, paso de víveres y mercancías y, sobre todo, lealtades en forma de servicios de vigilancia de las costas (por donde ingleses y holandeses podían acceder a las riquezas del interior continental) y de contención de los indios llamados "de guerra", que incursionaban en los asentamientos para robar ganado, atacar a los indios encomendados y secuestrar mujeres y niños españoles.

Estos intercambios conformaban un conjunto de actividades muy lucrativas, tanto así que no cabe duda de que la perduración de la frontera se debió, en parte, precisamente a los intereses económicos creados por la dinámica misma de las hostilidades.

\section{LA MEDIACIÓN LINGÜÍSTICA EN EL CONTEXTO DE LAS NEGOCIACIONES FRONTERIZAS}

Los parlamentos de la frontera araucana fueron las instancias oficiales de negociación entre la administración colonial y las poblaciones que se encontraban al sur del Biobío. Sobre la base de una modalidad autóctona de reunión y negociación entre grupos, el jesuita español Luis de Valdivia (Granada 1562 - Valladolid 1642) instaura el parlamento como eje de la política que se conoce como de "guerra defensiva". A partir de entonces, y pese al fracaso, en definitiva, del modelo pacífico valdiviano, el parlamento será la instancia para negociar las paces y treguas durante el periodo colonial. La independencia no representó un cambio en la situación interétnica, y por lo tanto el modo de relación, ahora con las autoridades republicanas chilenas y con agendas distintas, siguió siendo, aunque por poco 
tiempo, el del parlamento ${ }^{13}$. Varios historiadores y antropólogos ${ }^{14}$ se han referido particularmente a los parlamentos y desglosado sus principales características formales: temario, lugar y organización previamente convenidos, gran número de asistentes del lado mapuche, con comitivas nutridas y población general, forma muy ritualizada de interacción, con exhibiciones de fuerza y habilidad, largos monólogos, diálogos formalizados que se sucedían siguiendo secuencia y jerarquía establecidas, ofrecimiento de regalos de la parte española y firma de actas con los respectivos acuerdos.

Estos parlamentos, veinticuatro principales entre 1605 y $1803^{15}$, eran grandes solemnidades que podían durar varios días. Se preparaban todos sus detalles con anticipación, celebrando reuniones sectoriales: las "parlas" o "juntas de indios", y tenían lugar en un lugar convenido, reuniendo a cientos o incluso miles de personas, entre españoles y mapuches.

\begin{abstract}
"Más que ninguna otra institución, los parlamentos eran puntos de encuentro de la sociedad fronteriza y expresiones simbólicas del rico mundo político y social que emergía en la periferia del mundo hispano. Junto con los ataviados caciques, ulmenes y longos y las innumerables escuadras de conas, mujeres y weñes, acudían a los llanos del parlamento los misioneros, hacendados, comerciantes y milicianos que servían de escolta al gobernador, al obispo y a los jefes del ejército. Los parlamentos eran reuniones sociales en que se practicaba la política fronteriza y se renovaba el consenso que permitía el desenvolvimiento pacífico de las relaciones cotidianas"16.
\end{abstract}

José Manuel Zavala, quien ha estudiado los parlamentos desde el punto de vista antropológico, pone de manifiesto su lógica indígena, tanto en su definición como en los elementos formales y simbólicos, y sostiene que tienen su antecedente más directo en las grandes concentraciones rituales que solían celebrar los cuatro butalmapus, o parcialidades tradicionales ${ }^{17}$. En algunas crónicas españolas estas concentraciones se llaman despectivamente "borracheras", pero en otras son conside-

13 El último se celebró en 1864. Se considera que a partir de ese momento se da la "pacificación" definitiva de la Araucanía, que implicó la expropiación y subasta de las tierras mapuches. Todavía en 1907, auspiciado por el padre capuchino Sigifredo de Frauenhäusl, tiene lugar un último parlamento (así nombrado, aunque por tratarse de un encuentro de caciques mapuche debería ser más bien una junta), el de $\mathrm{Coz} \mathrm{Coz}$, para nombrar un representante que pudiera llevar a las autoridades la inconformidad por los abusos de los blancos. Véase, a este respecto, Carmen Arellano et al. (eds.), En la Araucanía. El padre Sigifredo de Frauenhäusl y el Parlamento mapuche de Coz Coz de 1907, Madrid y Frankfurt, Vervuert, 2006.

14 Véase Luz María Méndez, "La organización de los parlamentos de indios en el siglo XVIII", en Villalobos et al., op. cit., 107-174; Leonardo León Solís, Maloqueros y conchavadores en Araucanía y las Pampas, 1700-1800, Temuco, Ediciones Universidad de La Frontera, 1990; Horacio Zapater, La búsqueda de la paz en la Guerra de Arauco: Padre Luis de Valdivia, Santiago, Ed. Andrés Bello, 1992; José Manuel Zavala, "Aproximación antropológica a los parlamentos hispano-mapuches del siglo XVIII”, en Austerra 2, Santiago, 2005, 49-58.

15 El último parlamento histórico, ya en periodo republicano, fue en 1864. Luego, por ley de 1866, se decreta la soberanía de Chile sobre las tierras al sur del Biobío, y la reubicación de las poblaciones indígenas, lo que implica la liquidación definitiva de la Frontera.

16 León, op. cit., 147.

17 Zavala, op. cit. 
radas con particular respeto ${ }^{18}$. Según Zavala, la insoslayable asimetría política y militar no impidió que los indígenas impusieran y defendieran formas de negociación que les eran propias. El uso de intérpretes y el ritual de reconocimiento de los mismos al comienzo de cada parlamento son ejemplo de ello.

Los aspectos que se negociaban en los parlamentos eran principalmente el rescate e intercambio de cautivos, la protección de incursiones de indios de guerra, la protección y vigilancia de los embarques enemigos en las costas y la posibilidad de mandar misioneros a territorio mapuche y de crear misiones.

Los indios con los que se hacían los acuerdos o paces parlamentarias habían dado prueba de lealtad y fidelidad, comprometiéndose a no atacar a los españoles y a atacar, en cambio, a quienes pretendieran alzarse contra ellos. Se les conocía con el nombre de "indios amigos" o "indios de paz"19. Liberados por ello de las obligaciones que tenían los indios encomendados, acompañaban a los españoles en sus campañas contra los indios de guerra. Los capitaneaba un capitán de amigos, militar español o mestizo que vivía entre ellos, compartía autoridad con los caciques y servía de enlace con los españoles. El nombramiento de capitán de amigos, dependiente del Real Ejército, deriva según los historiadores de la función de intérprete ${ }^{20}$; el cargo surge en $1647^{21}$ y desaparece por decreto en 1832 , reapareciendo temporalmente hasta su desaparición definitiva a fines del siglo XIX ${ }^{22}$. Los capitanes de amigos, así como sus tenientes, eran un cuerpo militarizado de intérpretes e informantes que dependían de un funcionario superior, el comisario de naciones. Además de sus funciones de agentes de la administración colonial, encargados de dar salvoconductos para el paso fronterizo y reclutadores de lanzas para las correrías contra los indios de guerra, podían actuar como auxiliares de los misioneros, a quienes acompañaban en sus desplazamientos y servían de intérpretes. El tercer cargo oficial en estos cuerpos de mediación es el de lengua, o intérprete, general.

Los lenguas generales, capitanes y tenientes de amigos y comisario de naciones, todos ellos cargos militares, cuyas funciones encontramos unas veces más y otras menos diferenciadas, son los actores que más nos interesan en el contexto de los parlamentos.

Por la larga duración del periodo, el repertorio relativamente estrecho de situaciones en las que se requerían estos cuerpos de mediación, la formalidad de la remuneración y las posibilidades que ofrecía de obtención de bienes y favores,

18 Ver el tratamiento que da al tema de los parlamentos el jesuita Miguel de Olivares (17131793), en su "Historia Militar, Civil y Sagrada de Chile", recopilado en Colección de historiadores de Chile y de documentos relativos a la historia nacional, Santiago, Imprenta del Ferrocarril, 1861, v. 4, 83-85.

19 Andrea Ruiz-Esquide distingue entre "indios amigos" e "indios auxiliares" en el contexto del s. XVII. Entre estos últimos sitúa a los yanaconas: Andrea Ruiz-Esquide, Los indios amigos en la frontera araucana, Santiago, Dibam-Centro de Investigaciones Diego Barros Arana, 1993.

20 Véase Jaime Valenzuela Márquez, "La cordillera de los Andes como espacio de circulaciones y mestizajes: Un expediente sobre Chile central y Cuyo a fines del siglo XVIII", en Nuevo mundo Mundos nuevos 7, ISSN electrónico 1626-0252, 2007; Jorge Iván Vergara, La herencia colonial del Leviatán, Iquique, Instituto de Estudios Andinos, Universidad Arturo Prat, 2005.

21 León, op. cit., 160.

22 Vergara, op. cit., 226. 
resulta posible que se haya logrado una cierta especialización y prestigio de esta función social, cosa que confirma la existencia de dinastías o familias dedicadas a ello. En algunas familias hay varias generaciones de mediadores en distintos lugares del territorio:

\section{CLANES FAMILIARES Y CAPITANES DE AMIGOS}

\begin{tabular}{|c|c|c|c|c|}
\hline & 1767 & 1771 & 1774 & 1793 \\
\hline Salamanca, Manuel & Quechereguas & Malleco & Malleco & \\
\hline Salamanca, Pascual & ----- & ----- & Rucue & \\
\hline Salamanca, Agustín & ----- & ----- & Malleco y Renaico & \\
\hline Salamanca, Santiago & ------ & ----- & ----- & Cuinco \\
\hline Valdebenito, Joseph & Maquehua & ----- & Maquehua & \\
\hline Valdebenito, Pedro & ------ & & Canglo & \\
\hline Valdebenito, Santiago & ----- & Maquehua & & \\
\hline Valdebenito, José & ----- & ----- & ----- & Quillín \\
\hline Garrido, Simón & Tucapel & ----- & San Pedro & Colcura \\
\hline Garrido, Francisco & Albarrada & Albarrada & Albarrada & \\
\hline Garrido, Pascual & Tucapel & Tucapel & & \\
\hline Garrido, Rafael & ------ & ----- & Albarrada & \\
\hline Garrido, Agustín & ----- & ----- & ----- & Imperial \\
\hline Xara, Antonio & ----- & Llamuco & & \\
\hline Xara, Manuel & ----- & Antuco & Antuco & \\
\hline Xara, Luzgardo & ----- & Antuco & Antuco & \\
\hline Xara, Juan & ------ & ----- & ------ & Colque y Requen \\
\hline Rey, Juan & ----- & ----- & Colque y Requen & ----- \\
\hline Rey, Ignacio & ----- & Borca & Minas & Minas \\
\hline Rey, Pascual & ----- & ----- & & Colque y Requen \\
\hline
\end{tabular}

Fuente: Leonardo León Solís, The policy towards the Araucanian during the XVIII and XIX Centuries in Argentina and Chile, Tesis doctoral, Universidad de Londres, 1991.

Por su parte, el comisario de naciones era un cargo duplicado: se nombraba uno para Valdivia y otro para la Araucanía. Aunque conocedor de la lengua mapudungun e intérprete, como el caso de Narciso Pineur, que fue lengua general veinticinco años antes de ser comisario de naciones ${ }^{23}$, tenía sobre todo como función dar fe de los acuerdos a los que llegaban los hispano-criollos y los mapuches, por lo que se le encuentra presidiendo los parlamentos; actuaba además como juez y árbitro

23 Ibid., 259. 
en las desavenencias entre la población mapuche y en general sus funciones dependían de los vaivenes de la convivencia fronteriza: más visibles en periodos de movimiento militar y menos en tiempos de $\mathrm{paz}^{24}$. La imbricación entre los cargos de lengua general y capitán o teniente de amigos puede verse en particular en el caso de la familia Aburto, que ejerció prácticamente el monopolio de las relaciones interétnicas en la plaza de Valdivia durante tres generaciones.

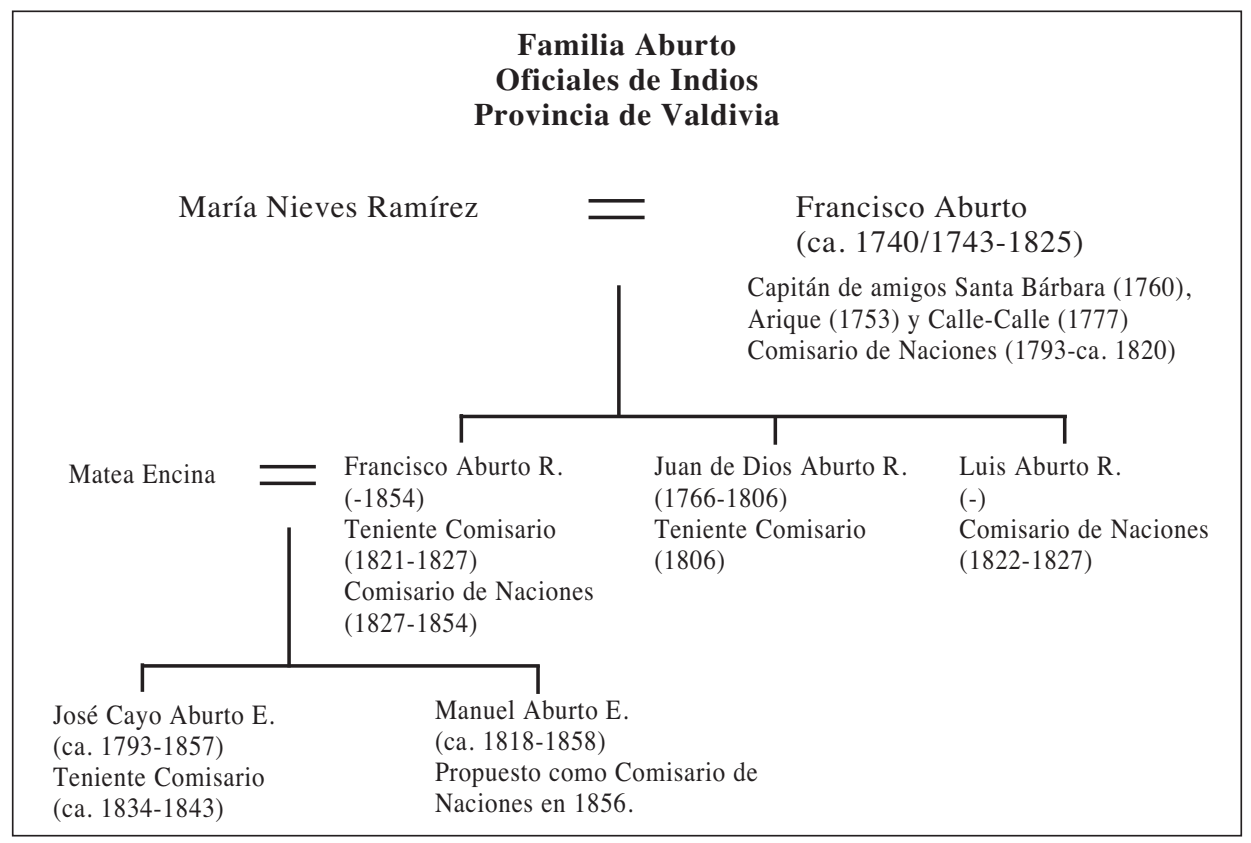

Fuente: J. I. Vergara, La herencia colonial del Leviatán, Iquique, Instituto de Estudios Andinos, Universidad Arturo Prat, 2005.

El lengua general, cargo con el que completamos este panorama de la mediación diplomático-militar y lingüística, se distingue de los lenguas o lenguaraces que operaban en situaciones ordinarias más o menos formales, en que tenía cargo oficial, con remuneración, y estaba sujeto a la reglamentación de las Leyes de Indias respecto a los intérpretes y, en particular, a lo referente a los indios de Chile $^{25}$. Se trata también de un cargo militar, como el caso de los capitanes Juan Bautista Pinto y Luis de Góngora ${ }^{26}$, que sirvieron de intérpretes al padre Luis de

24 León, op. cit., 173-74.

25 Ver el capítulo "De los intérpretes" así como la Ley VIII del título 16, referente a los Lenguas Generales, en el caso de Chile en: Recopilación de las Leyes de los Reynos de las Indias, mandadas a imprimir y publicar por orden de Carlos III en 1776, ed. facsímil de la reimpresión de 1791, Madrid, Consejo de la Hispanidad, 1943.

26 Hijo, al parecer mestizo, del cronista del mismo nombre. 
Valdivia en los años 1612-1614, en sus desplazamientos para llevar a los mapuches la noticia del fin del servicio personal.

En los estudios históricos no hemos encontrado singularizado el cargo de lengua general, a diferencia de los cargos de capitanes de amigos o comisario de naciones, en los que estaban combinadas las habilidades lingüísticas con las funciones administrativas y militares. En las fuentes encontramos a veces confundidos o asimilados los nombramientos ${ }^{27}$, y la nomenclatura con que se les designa es variable: "lengua general del ejército", "lengua general del reino", "intérprete general", a veces con mención del lugar en que operaban: "lengua general de la plaza de Valdivia". Habiendo recibido mucha menos atención en la historiografía, nos es preciso espigar en las crónicas y en los estudios modernos para recoger la información necesaria que nos permita establecer el perfil preciso de esta función de mediación, que al igual que la del capitán de amigos, no desaparece sino hasta entrado el siglo XIX ${ }^{28}$.

Capitanes, lenguas generales y comisario actuaban en conjunto en el contexto de los parlamentos, y podemos afirmar que estaban al servicio de los españoles y traducían para ellos principalmente. En las actas no figuran intérpretes del lado mapuche, aunque no se descarta que los hubiera, sabiendo que algunos caciques tenían "secretarios" 29.

El origen de los parlamentos no está totalmente dilucidado. Es sabido, eso sí, lo mucho que deben al jesuita granadino Luis de Valdivia. Los historiadores Horacio Zapater y Hugo Rosati relacionan la estrategia de negociación parlamentaria empleada en la frontera mapuche con la política del virreinato de la Nueva España respecto de la frontera chichimeca ${ }^{30}$, recordando que durante su estancia en Lima el padre Luis de Valdivia tuvo contacto personal con don Luis de Velasco, quien, siendo virrey de Nueva España entre 1590 y 1595, había propiciado un cambio de estrategia para la pacificación de los chichimecas en la que el uso de las armas quedaba relegado a favor de un proceso de transculturación ${ }^{31}$ en el que los pactos y negociaciones ocupaban un lugar preponderante ${ }^{32}$.

27 "El lengua o capitán que les damos, en pocos meses que está en sus reducciones, olvida el ser de cristiano [...]". Citado en Horacio Zapater, "Parlamentos de paz en la guerra de Arauco (16121626)", en Sergio Villalobos et al., Araucanía, Temas de historia fronteriza, Temuco, Ed. Universidad de La Frontera, 1989, 53.

28 Sabemos, por ejemplo, que en la plaza de Valdivia, los dos últimos lenguas generales fueron Juan de Castro (1775-1796 aprox.) y Bernardo Montecinos (1800-1818 aprox.). Vergara, op. cit.

29 Véase Florencia Roulet, "Mujeres, rehenes y secretarios. Mediadores indígenas en la frontera sur del Río de la Plata durante el período hispánico", Actas del $52^{\circ}$ Congreso Internacional de Americanistas, Sevilla, Secretariado de Publicaciones, Universidad de Sevilla, 2007.

30 Zapater, "Parlamentos de paz...", op. cit. Véase también Hugo Rosati Aguerre, "El imperio español y sus fronteras: mapuches y chichimecas en la segunda mitad del siglo XVI", Historia 29, Santiago, 1995-1996, 391-404.

31 Zapater, "Parlamentos de paz...", op. cit., 53.

32 No obstante, debe tenerse en cuenta que los chichimecas nunca fueron tratados como una nación independiente, como fue el caso de la Araucanía. 
A este respecto, Cecilia Sheridan ${ }^{33}$ señala que en la frontera del noroeste novohispano existía ya la costumbre de reunirse distintos grupos en un lugar previamente pactado para realizar alianzas e intercambios y prepararse para atacar enemigos comunes. A esta forma de reunión autóctona se le da en las crónicas el nombre náhuatl de tlatole $^{34}$, que significa discurso, parla, parlamento, conversación o chisme. Sobre esta tradición antigua parece haberse instaurado algún modo de negociación, aunque no tan desarrollado ni claramente tipificado como el caso de los parlamentos de la Araucanía.

No obstante estas similitudes, que confirman la existencia de un modelo de interpretación de la realidad autóctona y el uso de elementos preexistentes para establecer nuevas formas de negociación, nos parece también importante destacar un dato que no ha sido profundizado en la historiografía: el padre Luis de Valdivia nace en Granada en 1562, y llega a Chile en 1605, acompañando al gobernador electo, Alonso García Ramón, que era consejero militar del virrey Luis de Velasco y entre cuyos méritos estaba el de haberse enfrentado a los levantamientos moriscos en Granada ${ }^{35}$.

Cuando Luis de Valdivia llega a Chile no se han apagado todavía los conflictos en la frontera hispano-árabe. En su niñez se había producido la larga y violenta rebelión de las Alpujarras (1568-1571), que terminó con el destierro de la población morisca de Granada y su dispersión por toda España. En su entorno familiar se hablarían las dos lenguas y sabría de las formas de comunicación que tenían entre sí las dos comunidades. Criado en ese clima multicultural y conflictivo, y formado por la Compañía de Jesús, cuyo papel en la conversión de los moriscos es conocido, el padre Valdivia estaba bien pertrechado para su labor en otras tierras de infieles.

El padre Valdivia y el nuevo gobernador son quienes llevan a Chile la orden de terminar con el servicio personal de los indios, que había sido causante de descontento y rebelión indígenas y acarreado desastres militares y toma de mujeres y niños españoles como cautivos. También abogará por una política de guerra defensiva, como se había puesto en marcha en los territorios irredentos de la Chichimeca.

Es posible, pues, que si bien el antecedente más directo de los modos de negociación en la frontera araucana puede ser el de la Chichimeca pacificada por medios defensivos por el virrey Velasco, en lo tocante a la institucionalización de los modos de mediación, y en particular a la figura del intérprete o mediador lingüísti-

33 Cecilia Sheridan Prieto, "Indios amigos. Estrategias militares en la frontera noroeste novohispana", en Juan Ortiz Escamilla (coord.), Fuerzas Militares en Iberoamérica, siglos XVIII y XIX, México, El Colegio de México, El Colegio de Michoacán, Universidad Veracruzana, 2005, 27-46.

34 Tlatoa: "hablar". Palabra probablemente traída por los mismos misioneros, o por las familias tlaxcaltecas, hablantes de náhuatl, que habían sido trasladadas por las autoridades hacia la frontera como parte de la política de aculturación de los grupos chichimecas. En su acepción peyorativa de "chisme", posiblemente reforzada por los misioneros, recuerda el matiz peyorativo dado también al cahuín mapuche.

35 Hay que recordar que la expulsión de los moriscos (españoles musulmanes convertidos forzosamente al cristianismo por decreto de los Reyes Católicos en 1502) se promulga en 1609. 
co, la experiencia más profunda y duradera para los españoles debe haber sido la de la frontera hispano-árabe.

La figura más sobresaliente en las negociaciones hispano-árabes, y personaje característico de la frontera medieval entre el islam y la cristiandad es el alfaqueque (ss. XIII-XVII). La voz "alfaqueque" o "alfaquí" (ss. XIII-XVI), "alfaquequi" (s. XIV) o "alhaqueque" o "alaqueque" (s. XV) procede del árabe al-fakkâk, que significa "redentor de cautivos" y designa al que tenía como oficio redimir cautivos y libertar esclavos y prisioneros ${ }^{36}$. El diccionario etimológico de Corominas y Pascual $^{37}$ nos recuerda que, tanto en castellano como en portugués, este término existe también en su acepción de "parlamentario", como sinónimo de "exea" o mensajero: se trata de un emisario enviado para concertar una tregua o la paz y que, exactamente igual que el redentor de cautivos, debía adentrarse para ello en tierras enemigas. En algún momento se utilizó como sinónimo otro término de origen árabe, "turguman" o "trujamán”, para referirse en general a la persona que mediaba entre cristianos y musulmanes.

Esta pluralidad en las denominaciones y en las funciones que desempeña el mediador medieval nos parece un rasgo característico de la frontera granadina con los reinos de Castilla y Aragón. Efectivamente, en ella encontramos a los trujamanes, alfaqueques, exeas y elches, con tareas que a veces se solapan entre sí. A esta misma variedad de roles, unas veces más delimitados y otras menos, nos hemos referido también en las líneas precedentes para describir las tareas del mediador en la frontera colonial araucana y los distintos cargos oficiales allí existentes.

En el contexto fronterizo andaluz se generaron multitud de contactos vecinales de uno y otro signo y, a partir de ahí, necesidades concretas de mediación lingüística. Los alfaquíes o alfaqueques acudían a canjear o rescatar cautivos a tierras de infieles (ya fueran estos musulmanes o cristianos), pero también trabajaban en los puertos, firmaban otorgamiento de escrituras de propiedad de tierras, cartas de alcaldes y señores musulmanes a las autoridades cristianas, y viceversa.

Tenemos noticias documentadas de los alfaqueques desde el siglo XI, pues aparecen mencionados en los fueros y cartas puebla de muchas ciudades recién repobladas en las líneas de los ríos Duero y Tajo (y más al sur, a medida que la frontera se fue desplazando hacia Granada). A menudo compaginaban las tareas de rescate de cautivos con otras actividades, por cuenta propia o ajena: negociadores, agentes comerciales, consejeros y diplomáticos. De hecho, el catálogo de situaciones en las que operaban es muy similar al de la frontera hispano-mapuche, con su mezcla de diplomacia militar, espionaje de las costas y asistencia en cuestiones administrativas. Coinciden también con los capitanes y lenguas de la frontera chilena en el amplio margen de maniobra que les daba su conocimiento de las dos culturas.

36 James Williams Brodman, "Municipal Ransoming Law on the Medieval Spanish Frontier", en Speculum 62, Cambridge, 1985, 328.

37 Joan Corominas y José Antonio Pascual, Diccionario Crítico Etimológico del Castellano e Hispánico, Madrid, Gredos, 1980. 
El oficio se inició primero con los alfaqueques privados y municipales, que trabajaban por encargo de particulares y de órdenes religiosas en un caso, o bien contratados por los concejos municipales de las ciudades próximas a las líneas fronterizas. Los alfaqueques eran, sobre todo, buenos conocedores de las lenguas y culturas en contacto, aunque en su selección y nombramiento primaba también el criterio de lealtad política al grupo o a la persona que los contrataba, el ser dignos depositarios de la confianza otorgada, aunque su origen fuera en muchos casos judío, musulmán o converso. Su oficio, propio de zonas fronterizas, los vinculaba a ambos bandos y les ofrecía innumerables ocasiones de negocio y enriquecimiento personal -gozaban de salvoconductos para moverse libremente por el territorio- gracias a los contactos y relaciones que el cargo les proporcionaba.

En la segunda mitad del siglo XIII, Alfonso X el Sabio intentó neutralizar las posibles arbitrariedades de un mal ejercicio profesional, regulando en Las Siete Partidas los aspectos más controvertidos del oficio (posibles casos de soborno, prevaricación o traición) y fijando los requisitos de acceso al cargo y la obligación de respetar un código ético muy estricto, además de las normas para la redención de cautivos establecidas por ambos bandos. Desde el punto de vista normativo, la iniciativa alfonsina supuso reglamentar definitivamente y durante toda la Baja Edad Media una actividad que llevaba décadas realizándose, aunque como norma jurisdiccional vigente funcionaron los ordenamientos de Alcalá de Henares dados en $1348^{38}$. A ello se añadieron más adelante las numerosas disposiciones legales dictadas por los Reyes Católicos, Carlos V, Felipe II y Felipe III.

Con el correr del tiempo, y motivada por el afán de control y fiscalización de estas actividades, se crearía en 1439 una institución típicamente fronteriza de la España medieval: la Alfaquequería Mayor de Castilla. El cargo real, que se había ido perfilando durante el siglo XIV, recayó en Juan de Saavedra y coexistió con los alfaqueques municipales que trabajaban para los concejos, muy remisos a perder sus derechos ${ }^{39}$. El puesto tenía carácter hereditario y fue desempeñado durante décadas por la dinastía sevillana de los Saavedra, señores del Viso y de Castelar de la Frontera ${ }^{40}$. Tuvo vigencia oficial durante casi dos siglos, hasta 1620 , cuando fue abolido por decreto de Felipe III.

38 Manuel García Fernández, "La alfaquequería mayor de Castilla en Andalucía a fines de la Edad Media. Los alfaqueques reales”, en José Enrique López de Coca (ed.), Estudios sobre Málaga y el Reino de Granada en el V Centenario de la Conquista, Málaga, Diputación Provincial, 1987, 38.

39 Ibid., 37 y 40.

40 Según Mercedes Abad hubo otros casos de linajes de alfaqueques o intérpretes: Mercedes Abad, "Aquí hay necesidad de persona capaz en muchas lenguas. El oficio de intérprete en las últimas fronteras de Castilla", en Revista electrónica de estudios filológicos 10, 2005, 30 pp. 


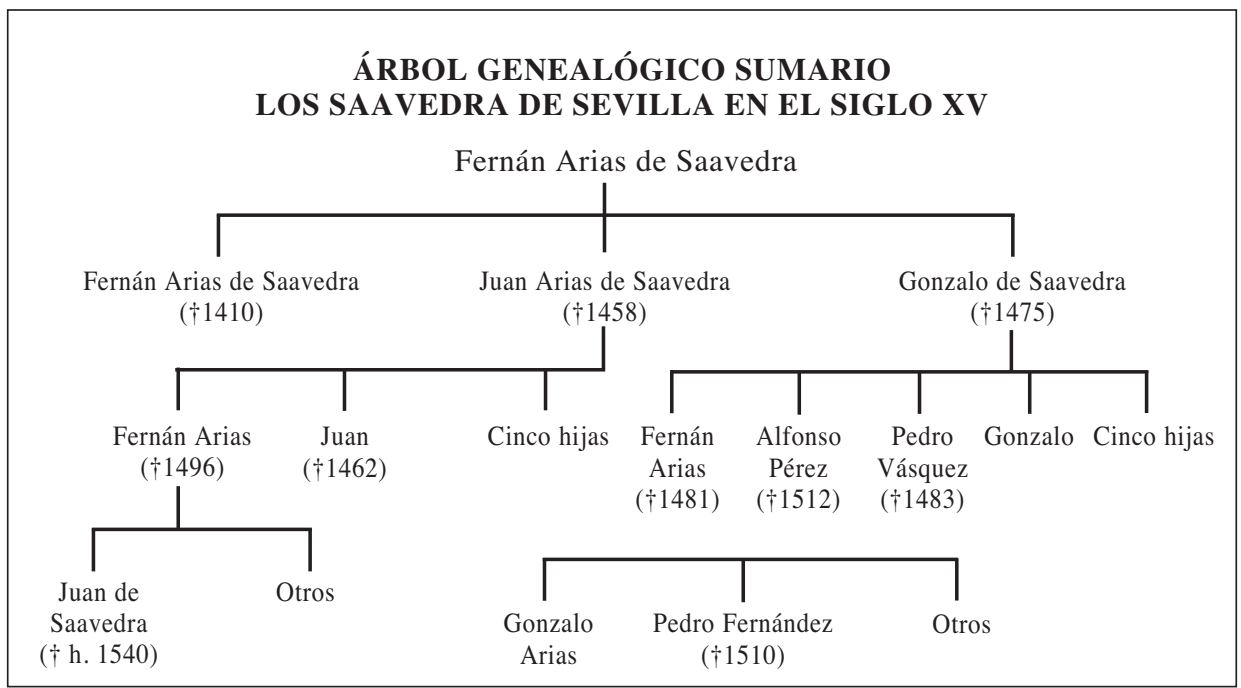

Fuente: R. Sánchez Saus, "Los Saavedra y la frontera con el reino de Granada en el siglo XV", en López de Coca, op. cit. En negrita la línea de transmisión hereditaria de los alfaqueques mayores.

\section{CONCLUSIONES}

La presencia de cuerpos de mediación lingüística formalizada y de larga duración es propia de las situaciones de contacto oficiales entre naciones ${ }^{41}$ que se reconocen mutuamente algún derecho de negociación. Las situaciones que conocemos como de frontera, con su dinámica de pactos y treguas, son particularmente ilustrativas de esta actividad formalizada, pero no son las únicas ${ }^{42}$.

Tanto en el caso hispano-mapuche como en el hispano-árabe se trata de casos de regiones fronterizas en las que coexistieron, se enfrentaron y se sometieron modelos políticos, militares, religiosos y culturales muy antagónicos. La permanencia del conflicto durante largos espacios de tiempo dio lugar a unas zonas fronterizas relativamente inestables, fácilmente alterables, en los que se sucedían periodos de paz y de guerra. En estas condiciones la frontera no deja de ser una zona de fricción, pero también de ósmosis e influencias recíprocas, un espacio donde la gente de a pie se enfrenta y convive, estableciendo relaciones, unas veces

41 Conservaremos el término naciones para hablar indistintamente de la monarquía española y de la sociedad mapuche.

42 El término de frontera no define estrictamente la actividad de interpretación formalizada. Hay que pensar más bien en una frontera simbólica, como en el caso de las negociaciones en los años 1995 de San Andrés Larraínzar, entre el gobierno mexicano y el Ejército Zapatista de Liberación Nacional (EZLN), en las que ejercieron intérpretes por primera vez entre las autoridades nacionales y los representantes de la población sublevada. 
violentas y otras pacíficas, y contactos vecinales, comerciales e incluso cultura$1 \mathrm{es}^{43}$. De modo que forzosamente la frontera instaura al mismo tiempo un espacio de traducción, donde la alteridad se acepta y se rechaza en función de intereses personales y colectivos. En él emergen de forma espontánea una serie de instituciones, personajes y negocios típicamente fronterizos, situados también en la frontera de los mestizajes biológicos: mercaderes o conchabadores, almogávares o maloqueros, capitanes de amigos o alcaldes de la frontera, aventureros, cautivos, informantes o espías, renegados, todos ellos con capacidades lingüísticas más o menos desarrolladas para operar como agentes interlingüísticos e interculturales, y en forma particular, los intérpretes (lenguas, farautes o alfaquíes en sus diversas denominaciones) como institución, con atribuciones y remuneración definidas ${ }^{44}$.

Separar la interpretación formal de las actividades comerciales interculturales no debe hacernos olvidar que en no pocos casos hubo mezcla de funciones, ya que los intérpretes aprovecharon sus cargos para realizar negocios privados y actividades comerciales. Por otra parte, el carácter de intermediarios culturales de los comerciantes y otros oficios de intercambio los hacen lógicamente cercanos a los intérpretes.

Las formas más institucionalizadas de la mediación lingüística y cultural en las zonas de contacto aparecen cuando hay consolidación de intereses y reconocimiento mutuo de la necesidad de un tipo de negociación en la que, al menos en apariencia, se admite en la contraparte una capacidad de negociar. Por eso no se encuentran habitualmente en los albores de la Conquista, cuando las necesidades de conocimiento del otro se reducían a la exploración territorial, abastecimiento de tropa y detección de posibles enemigos, ni tampoco en situaciones de sometimiento absoluto. La posibilidad de ganancia en una interacción entre lenguas distintas, en circunstancias de relativa simetría, lleva al reconocimiento de la utilidad del intérprete $\mathrm{y}$, por lo tanto, a una mayor institucionalización de los cargos, con ratificación pública de la confianza que se les otorga: nombramiento y juramento del cargo, códigos implícitos o explícitos de actuación, relaciones de derechos y deberes, etc. Por la misma razón, las formas institucionalizadas de mediación lingüística se dan cuando la necesidad es reiterada o permanente (intercambio de cautivos, situaciones de conflicto prolongadas o recurrentes), lo que nos permite analizarlas con más profundidad, aprovechando la atención que ha prestado la historiografía más actual a estas situaciones y conflictos.

Si bien no se refiere particularmente a la frontera araucana ni al caso hispanoárabe, con la noción de "negociar las fronteras", en su trabajo sobre historia de la traducción, Anthony Pym propone un lugar para las interacciones culturales en el que los mediadores se despliegan como colectivo intersticial al que caracterizan ciertos rasgos comunes ${ }^{45}$. Pym habla incluso de una "intercultura" para definir el

43 García Fernández, op. cit., León, op. cit.

44 Michael Cronin subraya y explica especialmente la relación entre dinero y traducción. Ver Michael Cronin, Across the lines. Travel, Language, Translation, Cork, Cork University Press, 2000.

45 Anthony Pym, Negotiating the Frontier, Translators and Intercultures in Hispanic History, Manchester, St. Jerome Publ., 2000. Hay que advertir que Pym atribuye al intérprete una conciencia de sí y de su papel que posiblemente pocos tuvieron (y menos aún en situación bélica). 
fenómeno colectivo de los intermediarios lingüístico-culturales. Al analizar la historia de la frontera del Biobío y de la frontera hispano-árabe desde una óptica traductológica, además de reconocer el importante papel desempeñado por unas instituciones negociadoras o mediadoras representadas por los intérpretes ${ }^{46}$, hemos constatado que constituían espacios de poder suficientemente significativos como para ser apetecibles y, por lo tanto, monopolizables y heredables dentro del círculo familiar. La constitución, pues, de linajes o dinastías de intérpretes, que ya constatamos en el caso de algunos nahuatlatos novohispanos ${ }^{47}$, y que aquí hemos corroborado, parece avalar el enfoque intercultural de Pym. La profesionalización y especialización que de ello se deriva, así como la recurrencia del modelo de mediación lingüística fronteriza, justifican que queramos analizar estos fenómenos alejándonos de la forma aislada, personal o anecdótica con la que han sido tratados en la historiografía, y proponiendo un abordaje comparativo e interdisciplinar que sin duda contribuirá a conocer mejor el funcionamiento de estos colectivos.

Otra conclusión que parece surgir de este trabajo se sitúa precisamente en el plano de la ética traductológica: no encontramos nunca cuerpos formalizados de mediación intersocial sin una cierta correlación de fuerzas y sin reconocimiento mutuo de algún tipo de derechos. En el caso chileno la resistencia indígena y la existencia reconocida de intereses por ambos bandos, sumada a lo costoso que representaba para la hacienda española mantener un ejército en activo en ese "Flandes Indiano" fueron condiciones que contribuyeron a crear un clima de contención mutua de hostilidades donde pudieron darse estas instancias singularísimas que fueron los parlamentos, con sus órganos de mediación lingüística formaliza$\operatorname{dos}^{48}$. Asimismo, en el caso hispano-árabe, es la larga duración del conflicto y el entramado de intereses comerciales y diplomáticos que sustenta la marca hispánica lo que determina la larga presencia de alfaqueques y exeas.

El reconocimiento de la nación araucana y del califato de Córdoba y reino nazarí de Granada implicó unas estrategias de mediación afines a la práctica del derecho de gentes. Considerados desde la perspectiva de hoy, estos grupos institucionalizados de mediadores constituyen un eje importante en el largo y profundo proceso de transculturación. Como conocedores de varias culturas, tuvieron un margen de actuación seguramente envidiable en comparación con la población de uno y otro bando. También, justo es decirlo, estuvieron en la mira de ambos. Y fueron instrumentos, a sabiendas o no, de intereses individuales y colectivos.

Si bien en el conflicto actual en zona mapuche no se requerirían mediadores lingüísticos, no se puede dejar de considerar que cuando existe un aparato de mediación lingüística institucionalizado se introduce un tercer polo en la negocia-

46 La institucionalización de la mediación y de sus agentes en el caso de la frontera araucana, que podemos contrastar con la falta de institucionalización de la mediación en los contactos de conquista y exploración, y (¿por qué no decirlo?) que contrasta pasmosamente con la falta de institucionalización de la mediación en los contactos modernos de migración en Europa, instiga reflexiones que podemos situar en el ámbito de la ética de la mediación.

47 Alonso y Payàs, op. cit.

48 Diego de Rosales, Historia General del Reino de Chile, Flandes Indiano, segunda edición, revisada por Mario Góngora, Santiago, Ed. Andrés Bello, 1989. 
ción, de carácter amortiguador o neutralizador, cuya mera existencia ya significa reconocimiento de alteridad y voluntad negociadora.

Seguir estudiando las características pragmáticas y funciones simbólicas de la mediación lingüística del pasado podría contribuir a encontrar mejores modos de negociación en la situación actual del sur chileno. En el caso europeo que estamos estudiando paralelamente, la mera existencia de una legislación muy temprana sobre los oficios de mediación lingüística los convierte en un valioso antecedente para una profesión que las sociedades occidentales parecen redescubrir en las dos últimas décadas, al calor del fenómeno migratorio. 
